\title{
Escuta de uma experiência psicótica amparada no método junguiano: mater ecclesiae
}

\section{Listening of a psychotic experience supported on the Jungian method: mater ecclesiae}

\section{Escucha de una experiencia psicótica cubierta por el método junguiano: mater ecclesiae}

\author{
Emanuel Cesar Proença Simões* \\ Universidade Federal de São J oão del-Rei - UFSJ, Minas Gerais, Brasil
}

Filipe de Menezes J esuino**

Dialogus Clínica de Psicologia, Ceará, Brasil

\begin{abstract}
RESUMO
Temos como objetivo apresentar como um sujeito, em sua experiência psicótica, pode se beneficiar do atendimento individual apoiado na psicologia junguiana. O trabalho constitui-se a partir do estudo do desenvolvimento psicológico de uma usuária de um Centro de Atenção Psicossocial, em município do interior do nordeste brasileiro, enquanto acompanhada por um profissional de psicologia que trabalhou com o método junguiano. Trata-se de um estudo qualitativo abordado pelo relato de caso; as fontes das informações são o prontuário da paciente no Centro de Atenção Psicossocial e o diário de campo das observações clínicas, convertidos em dados pelo processo empírico-descritivo. Os dados são os relatos resultantes de um processo terapêutico abordado segundo o método redutivo e construtivo de Jung. A análise se orienta das interpretações redutiva e construtiva, articuladas como reflexão complementar aos significados já produzidos no próprio processo analítico. O acompanhamento contribuiu para a reconstrução do sentido de estar viva da mulher através da integração da experiência com a superação do sentido "doença mental" para "saúde mental", reduzindo o uso de antipsicóticos e a ocorrência das crises psicóticas e superando o efeito colateral de embotamento afetivo com uma reabilitação psicossocial germinal de sentido para a vida.
\end{abstract}

Palavras-chave: teoria junguiana, transtornos psicóticos, desinstitucionalização.

\begin{abstract}
Our goal is to present hohitak a person could benefit from its psychotic experience in a treatment based on the Jungian psychology. The work is a study of a CAPS user, in Brazilian northeast, while accompanied by a psychologist who worked with the Jungian method. It is a qualitative study addressed by the case report. The information sources are the patient's medical records from CAPS and the clinical observations' diary field, being converted to data by the empirical-descriptive process. The data are the
\end{abstract}


reports resulted from a therapeutic process addressed according to the reductive and constructive method of Jung. The data analysis is guided through both reductive and constructive interpretation, articulated as a complementary reflection on the meanings already produced. The treatment could contribute to the reconstruction of the meaning of being alive through the integration of the experience with change the meaning of "mental illness" to "mental health", achieving the reduction of the antipsychotics, reduction of the psychotic crisis, and the overcoming of the side effect of the affective dullness with a germinal psychosocial rehabilitation of meaning for life.

Keywords: Jungian theory, psychotic disorders, deinstitutionalization.

\section{RESUMEN}

Nuestro objetivo es presentar como un sujeto en su experiencia psicótica puede beneficiarse de una atención apoyado en la psicología junguiana. El trabajo es estudiar el desarrollo de una usuaria de un Centro de Atención Psicosocial del interior del nordeste de Brasil, acompañada de un psicólogo que trabajó con el método junguiano. Se trata de un estudio cualitativo dirigido por el reporte de un caso; Las fuentes de información son los registros del paciente en el CAPS y el diario de campo de observaciones clínicas, convierten a los datos por el proceso empírico-descriptivo. Los datos son los informes resultantes de un proceso terapéutico cubierto por método Jung. El análisis es guiado desde interpretaciones reductivas y constructivas, articulado como una reflexión complementaria sobre los significados ya producidos. Contribuido a la integración de la experiencia con la superación del sentido de "enfermedad mental" a "salud mental" mediante la reducción del uso de fármacos antipsicóticos y la aparición de las crisis psicóticas y superar el efecto secundario de afectiva aplanando con un germen de rehabilitación psicosocial de significado en la vida.

Palabras clave: teoría junguiana, trastornos psicóticos, desinstitucionalización.

\section{Introdução}

Este trabalho foi motivado pelo interesse na escuta da experiência subjetiva da psicose, uma vez que o sofrimento psíquico existencial ligado a essa condição é geralmente subsumido diante da comum associação com o estigma "loucura" ou "doença mental" (Costa \& Medeiros, 2007; Pessotti, 2006). Para iluminar esse tema, nosso objetivo de estudo é compreender a adaptação de um sujeito em sua experiência psicótica pelo atendimento individual amparado na psicologia junguiana.

Em contraste com este esforço, no contexto da atual Reforma Psiquiátrica brasileira (RPb), o Centro de Atenção Psicossocial (CAPS) - serviço comunitário da RPb de cuidado em liberdade, territorial, substitutivo ao modelo manicomial - tem destacado, através de suas práticas hegemônicas, a associação exagerada entre sofrimento psicótico e prescrição de psicotrópicos, socialmente legitimada pelo estigma da loucura: "A contenção física foi destronada em favor da química e esta se alastrou rapidamente" (J esuino \& Simões, 2014, p. 
163), pois, como destaca Isaias Pessotti (2006), “[...] graças à presumida produtividade creditada à psiquiatria dita biológica e ao DSM [...], o louco-sujeito, e a loucura como modo do 'ser no mundo', são hoje assuntos de reflexão filosófica" (p. 122).

Para a escuta da experiência psicótica à luz da teoria junguiana, devemos perguntar-nos sobre o interesse do sujeito ao se voltar, com atitude introvertida, para essas formações inconscientes (J ung, 1986). Nesse sentido, Jung (1986) é categórico e arremata: “[...] o método construtivo, para se manter fiel à sua natureza, deve se ajustar às pistas fornecidas pelo próprio sistema de delírios. [...] Deste modo, o investigador se coloca no ponto de vista da psicose" (p. 173).

Nosso argumento do olhar para a subjetividade psicótica, precedente a este trabalho (J esuino \& Simões, 2014), fortaleceu-se à medida que o contexto do lugar formativo da residência, um CAPS do interior do Estado do Ceará, passou a ser o contexto do atendimento de um psicólogo residente de referência psicológico-analítica a uma usuária que vinha sendo acompanhada pelo serviço com pouca ou nenhuma atenção à sua experiência subjetiva, quiçá a sua sociabilidade. Sua simbólica experiência psicótica contrastava com o tratamento centrado em antipsicóticos: a dose era aumentada a qualquer identificação de delírio. Este fez parte do material para compreender como a experiência psicótica contribuiu para uma adaptação do próprio sujeito.

Dessa forma, nossa discussão está entrelaçada com a indagação: Quais as contribuições e limites da psicologia junguiana no tratamento dos transtornos psicóticos? Para responder a essa questão, torna-se imperioso explicitar adiante o método da psicologia junguiana.

Reafirmando a relevância do conteúdo simbólico das psicoses e do interesse do sujeito nesse sentido (Barreto, 2011; Jesuino \& Simões, 2014; Jung, 1986, 1991a, 1991b), asseveramos o papel do método junguiano na integração de um projeto terapêutico que beneficia o próprio sujeito em sua história subjetiva e na adaptação da sua personalidade, bem como articulamos, ao longo da discussão de resultados, possíveis contribuições do referido método para a desinstitucionalização do estigma "loucura" em relação às psicoses (Alverga \& Dimenstein, 2006; Costa \& Medeiros, 2007; Jesuino \& Simões, 2014; Melo, 2007).

\section{Metodologia}

O relato de caso é referente ao atendimento psicossocial a uma usuária entre quarenta e cinquenta anos de idade, com histórico de internações psiquiátricas por surtos psicóticos de cunho místico religioso e posterior tratamento em CAPS, principalmente nos moldes 
do atendimento queixa-conduta, centrado na doença, ignorando a subjetividade na concretude do seu território vivo.

Além de compreender a adaptação do sujeito pela experiência psicótica, temos como objetivo articular essa compreensão a possíveis contribuições da prática do método junguiano para "[...] a ética da desinstitucionalização" (Amarante, 1996, pp. 110-115). Tal articulação será feita ao longo do texto, especialmente na discussão de resultados.

Nesse sentido, a prática do método junguiano, pelo resgate da subjetividade da psicose, parte da atitude de recusa de silenciar a existência em sofrimento atravessada pelo quadro psicótico (Jung, 1986), seja pelo silenciamento com o estigma da loucura, seja pela violência da redução da existência complexa a um epifenômeno de uma disfunção anatomofisiológica (Amarante, 1996), seja pela redução de uma visão psicológica racionalista apenas causal-linear que exclui a complementação do valor simbólico das imagens inconscientes no desenvolvimento psicológico do sujeito (Jung, 1986). Desse modo, um método complexo como o de Jung (1986) é oportuno para o que Rotelli (1990) alertou sobre a psiquiatria, uma vez que esta se instituiu sobre a separação de um objeto construído na sua visão biomédica - a doença - da existência vivida pelo sujeito em sua relação com a sociedade.

Em consonância com a rearticulação da então desvalorizada experiência psicótica, a psicologia complexa de Jung (1986) já buscava revelar os mistérios da psique nessa experiência: o método construtivo reconhece a exigência de complementação da racionalidade redutiva-causal pelo ato de caminhar lado a lado com o sujeito na construção de sentido da sua experiência, aproximando-se o máximo possível do ponto de vista do simbolismo das imagens inconscientes.

Trata-se de um estudo qualitativo abordado pelo relato de caso; as fontes das informações são o prontuário da paciente no CAPS e o diário de campo das observações clínicas, convertidos em dados pelo processo empírico-descritivo (Jung, 1986, 1991a, 1991b). Os dados são o relato da experiência clínica resultante do processo terapêutico. Para o acesso ao prontuário, foi necessário viajar para retornar até o serviço de referência descrito.

Para a discussão dos resultados, procedemos inicialmente com a descrição geral do caso e a organização da coerência do acompanhamento a partir de como a experiência de surto psicótico atuou como fator de organização do cuidado relatado. A análise dos dados se orientou primeiro através da interpretação histórico-redutiva (causal), que consiste em apontar os fenômenos como sintomas de condições que os predispõem, internas e externas. Segundo, pela interpretação construtiva, que, de forma simbólica, aponta tendências de realização subjetiva pela produção de sentidos prospectivos. 
Portanto, a simples redução do desconhecido ao conhecido não pode substituir o caráter finalístico do fenômeno simbólico.

Podemos destacar como limitação do estudo as escassas informações sobre a infância da usuária, não obstante as informações colhidas tenham sido suficientes para uma interpretação histórica. Uma investigação aprofundada sobre as possíveis contribuições do método junguiano à desinstitucionalização deve ser objetivo de outro estudo. A pesquisa foi aprovada pelo Comitê de Ética em Pesquisa com Seres Humanos da Escola de Saúde Pública do Ceará (ESP/CE) pelo Parecer no 1.093 .351 .

\section{Discussão de Resultados}

Com base no método junguiano e nas informações coletadas, organizamos a discussão de resultados através de quatro campos de análise: organização do problema investigativo do caso, interpretação redutiva, interpretação construtiva e refiguração.

\section{Organização do Problema I nvestigativo do Caso}

Nesse campo, buscamos organizar a compreensão de como a experiência de surto psicótico pôde atuar como fator de adaptação do próprio sujeito e, consequentemente, de (re)organização do cuidado relatado, envolvendo acompanhamento psicológico articulado ao cuidado interprofissional no CAPS.

O caso diz respeito a uma usuária da rede pública de saúde mental com sofrimento por crises identificadas como transtornos psicóticos. 0 sujeito estava vivendo um momento de grande sofrimento na vida quando, em determinada noite de insônia, "alucinou" uma imagem que, mais tarde, a própria paciente comparou com as imagens de Nossa Senhora de Aparecida. Embora, por vezes, achasse também que era Nossa Senhora de Fátima. Inicialmente estática durante a visão, "tomada, dominada", pouco tempo depois, "bateu o medo", o que é típico da reação diante do numinoso (Jung, 1991a; Otto, 2011). A mulher perdeu o controle, gritou e correu desesperadamente: “[...] eu não estava doida, eu estava com medo".

Após esse momento, a usuária quis ir à igreja para ver os santos, mas sua vontade foi ignorada; ela foi levada para a internação psiquiátrica: "Eles me levaram porque não sabiam, tinham medo d'eu... [eu] bolava no chão... a santa me fazia correr, ela apareceu e veio o oposto, o bem e o mal [...]".

Após mais de dez anos de tratamento no modelo manicomial, a usuária foi cuidada em meio aberto no CAPS: mas com o centramento no uso de psicotrópicos. A escuta interessada naquela experiência não foi oferecida, restava a sombra manicomial com os 
desejos de manicômio (Alverga \& Dimenstein, 2006; Jesuino \& Simões, 2014).

Desde que oferecemos essa escuta interessada na experiência da sua primeira crise, a mulher referiu-se a uma felicidade que não sabia explicar "[...] é felicidade, mas não sei explicar... não tá [sic] acontecendo nada... é de Deus... eu nunca tive médico [psicólogo] como você... antes era só receita... [mas] até o remédio eu tomo... sem achar tão ruim como antes".

Embora tivesse passado a aceitar a medicação, permaneciam as queixas de "tontices" [sic] e "vista confusa"; e continuava o medo de ter novas crises, quando "[...] a cabeça esquenta, vem uma força medonha, dá medo de cair e se debater, dá força pra [sic] correr, e parece que todo mundo tá [sic] dentro da cabeça".

Esse medo das crises ocorria sempre que se percebia uma falta de sentido na vida devido ao excesso de psicotrópicos. Não à toa, pois, quando a psiquiatria identificava o delírio místico, a dosagem de antipsicóticos era aumentada, com argumentos nosográficos que identificavam confusão, baixa cooperação, delírio, autocrítica e juízo crítico prejudicados.

Isso se explica na medida em que à imolação do delírio correspondia a destruição da sua tentativa de construção de sentido (Jung, 1986), que, por sua vez, implicava essa eventual falta de sentido. Esse era o fator desencadeador do estado de desânimo identificado por ela como precursor de surtos, como um fenômeno de enantiodromia (Jung, 1985).

Uma compensação mais equilibrada à falta de sentido foi a emoção ante a escuta e a valorização do discurso sobre sua experiência: "[...] 0 coração quer descer para o peito", ressaltando efeito oposto à indiferença emocional provocada pelas drogas quando "[...] o coração [vai] para a cabeça... nada presta, não gosta de sair, sente-se desanimada... vista encandeada, as coisas embaraçadas, sente corpo pesado e sono". A paciente reiterava que o lugar certo do coração é no peito; afirmava que também gostaria de aprender a se controlar (ao que ela relacionava a unir duas personalidades em uma só, a do coração no peito e a do coração na cabeça).

Finalmente, ela arremata - conclusivamente - que o histórico de malestar e falta de sentido que ainda se atualizava em sua vida era devido à falha na escuta da sua experiência pelos serviços de saúde mental por onde passou: "[...] se os médicos tivessem me ouvido como você está me ouvindo, eu não teria tomado tanto remédio". E talvez não tivesse sido internada tantas vezes! Em vista disso, a própria usuária começa a responder ao questionamento sobre a eficácia do método junguiano no tratamento dos transtornos psicóticos, ressaltando a importância da escuta da experiência como resposta à crise (J esuino \& Simões, 2014). 
Perseveramos, destarte, com a interpretação dessa escuta da experiência do surto psicótico da usuária por meio das interpretações redutiva e construtiva de Jung, que apoiaram o discernimento dos significados produzidos no atendimento clínico.

\section{I nterpretação redutiva}

Consoante a perspectiva de que a complementação construtiva sustenta a permanência relativa da análise redutiva-causal, Jung (1972) defende ainda outra hipótese etiológica, a química, mas assevera que não deve partir de uma pesquisa especificamente química, e sim de um processo de eliminação da hipótese psicológica. Nesse sentido, as investigações da psicofarmacologia são necessárias, não para o centramento terapêutico nos fármacos, pois há “[...] um longo caminho a percorrer até que a fisiologia e a patologia do cérebro, de um lado, e a psicologia do inconsciente, de outro, venham a se dar as mãos" (Jung, 1986, p. 258). Até lá, tais perspectivas de tratamento devem ocorrer separadamente, mas sem a pretensão de substituir uma pela outra:

Para ser claro, considero que a etiologia da esquizofrenia é dupla: a saber, até certo ponto, a psicologia é indispensável para explicar a natureza e as causas das emoções iniciais que originam as alterações metabólicas. Essas emoções parecem ser acompanhadas de processos químicos que causam transtornos específicos temporários ou crônicos ou lesões (1972, p. 272, tradução nossa).

À parte o centramento psicofarmacológico, descobrimos que a usuária foi criada em contexto familiar religioso, com pai, mãe e bastantes irmãos. Sua história pessoal com sua mãe está intimamente relacionada à temática católica, mas também à opressão pela família na infância, a qual se atualizou no seu casamento.

Ao resgatarmos o discurso sobre a crise pela primeira vez, acentuamos devidamente a associação da mulher com esses eventos: ela estava em momento de intenso sofrimento pessoal por perdas de filhos e por conflitos familiares, relacionados à violência com o feminino e à ausência de apoio social e espiritual.

Tal opressão, no entanto, foi confrontada pelo que esta visão da crise Ihe disse: "[...] fazei tudo o que eu mandar, não errai uma palavra". O sintoma passou a confrontar a opressão. À época, a usuária associou essa fala com "[...] não cometer erros e ser uma pessoa boa, nunca má ou errada, fazendo tudo certo". Diante disso, o sentido atribuído pela família e pelos profissionais de saúde era apenas um: doença mental.

A ordem da imagem era confrontada com a castração da mãe, que estigmatizava a aparição. Assim, parece haver um complexo materno 
de temor à mãe devoradora em oposição à imagem de Nossa Senhora (Jung, 1991a, 1991b). Não obstante sua tendência de interesse na ordem da santa, ela esbarrava com o histórico de abrir mão do próprio interesse pela vontade dos outros: família, comunidade e profissionais de saúde, os quais a desacreditavam ou a estigmatizavam por tal discurso de interesse. É certo que, após o surto da usuária, sua mãe trocou de religião. Saiu do catolicismo e se tornou evangélica, distanciando-se do tema da santa, fato que se refletia na vida da paciente pela confusão sobre qual religião seguir: católica ou evangélica, através da tentativa perturbada de frequentar ambas as igrejas. Em polarização a esse descrédito, a escuta atenciosa do analista fez crescer uma tensão energética oposta: o interesse da usuária na experiência.

\section{I nterpretação Construtiva}

As fantasias irracionais nos delírios e alucinações são tentativas de construção de sentido para lacunas da necessidade de desenvolvimento da personalidade empírica (J esuino \& Simões, 2014; J ung, 1986). Desse modo, explicitamos a diferença que consideramos entre psicose e loucura "[...] enquanto [a pessoa] puder explicar-se e eu sentir que podemos manter um contato, afirmarei que ele não está louco. [...] Usamos restrições e convenções sociais a fim de reconhecermos desequilíbrios mentais" (Jung, 1991b, pp. 30-31).

Afinal, qual o interesse do sujeito ao se voltar com atitude introvertida para essas formações inconscientes? A lacuna no desenvolvimento da personalidade da paciente parece estar presente nas suas queixas de submissão da sua vontade à vontade dos outros: "[...] não faço nada que quero, só o que mandam... desde que nasci". Destarte, é como se a usuária tivesse necessidade do surgimento de Nossa Senhora, uma vez que corresponde ao motivo típico da mater ecclesiae, o qual refere-se a poderes mágicos para ajudar os filhos carentes de sua graça (Jung, 1986, 1991a).

Paulatinamente à escuta da experiência na análise, surgiu uma oposição forte a partir da paciente entre o interesse na santa e o estigma dos constructos psiquiátricos. A projeção, antes alucinada e então delirante, perdeu energia quando a mulher percebeu que a ordem da santa era seu próprio interesse, provocando regressão da projeção, mas mantendo seu conteúdo, então vivenciado pela usuária na mudança de atitude, buscando a oração e a igreja, e no grande bem querer às pessoas - análogo ao amor de Nossa Senhora -, aproximando-se da assimilação da qualidade santidade. Jung, em 0 segredo da flor de ouro (1984), já distinguia esse fenômeno:

Muitos dentre os primeiros deuses passaram de pessoas a ideias personificadas e, finalmente, a ideias abstratas. Os conteúdos do 
inconsciente ativado aparecem primeiro como projeção sobre o mundo externo e, no decurso do desenvolvimento espiritual, são gradualmente assimilados pela consciência e transformados em ideias conscientes, perdendo seu caráter originário autônomo e pessoal. Como sabemos, alguns dos velhos deuses tornaram-se, mediante a astrologia, meras qualidades (marcial, jovial, saturnino, erótico, lógico, lunático etc.) (Jung, 1984, p. 48).

Com o desenvolvimento da análise, a usuária passou a manifestar fortes ideias sobre o "mundo de céu", como revela a seguinte visão, por "[...] intuição tão eminentemente 'psicológica"” (Jung, 1991a, p. 136), após o início da análise: “[...] vi acima do céu estátuas azuis, Deus, mas não dava pra [sic] ver sua cabeça, uma porta para passar e uma roda branca como a roupa de Deus... como a hóstia consagrada".

O paralelo entre imagem visionária e símbolo cultural mitológico da hóstia foi feito pela própria paciente. Então, realizamos amplificação cultural objetiva (Jung, 1986) para acompanharmos lado a lado a base subjetiva implicada para a usuária pelo ponto de vista inconsciente do qual ela se aproximava: o motivo da roda branca é "A unidade de vida e consciência é o Tao, cujo símbolo, a luz branca central, é semelhante à que é mencionada no Bardo Thödol" (Jung, 1984 , p. 41), a visão desses fenômenos luminosos - amiúde aludem a fenômenos da consciência, e estes, quando assumem tal formato central, geralmente representam o Si-mesmo em seu caráter unificador (Jung, 1991a). Já o da hóstia - associada pela mulher - é uma referência clara ao Cristo (Anthropos, imagem masculina mais próxima do Si-mesmo), motivo psicológico da redenção da humanidade pelo sacrifício do Salvador.

Não ocasionalmente, tal visão brevemente se tornaria nova projeção: dessa vez, no analista. Analogamente, é como se a ordem da santa começasse a deixar de ser "Fazei tudo o que eu mandar" para ser "Fazei tudo o que Ele vos mandar" (Evangelho de João 2, 1-12). Trata-se do primeiro milagre de Jesus ao transformar a água em vinho quando Maria, com essa ordem, dirigiu-se aos servos. Notavelmente, só após ser escutada em seu interesse pela ordem da santa (presenciando a mudança "da água para o vinho", como os servos), veio esse movimento oposto ao caos de imagens. Na projeção, o analista passou a exercer a função de apaziguador, personalidade mana e psicopompo projetado (Jung, 1991a, 2008): “[...] você é como Jesus [...] os olhos, você inteiro [...] todos dois é bom [sic], legal e paciente [terapeuta e Jesus] [...] Jesus ainda acalma as pessoas, e você também [...]. J esus está no CAPS". Há clara analogia entre a psicoterapia e um sistema religioso. No entanto, Jung (1991b) assevera: "Nem precisa dizer que tais imagens impessoais sobre o analista deva ser retirada [sic]. Mas somos capazes de 
dissolver apenas o ato da projeção. Não podemos nem devemos dissolver os seus conteúdos" (p. 149).

Como vimos, a relação psicoterapêutica passou a enredar a função de reflexão como "[...] observação cuidadosa e consideração de certos fatores invisíveis e incontroláveis do inconsciente" (Jung, 1988, p. 12) para a própria usuária - literalmente, um espelho -, de modo que, antes perturbado pela multidão quando "a cabeça fica cheia de gente", o inconsciente, agora personificado na imagem central de Jesus, finalmente apaziguou a multidão pela projeção no analista. Trabalhada, a projeção regrediu para tornar-se conteúdo de meditação sobre a imagem do analista associada à de Jesus, quando esta surgia introspectiva e intuitivamente (Jung, 2008): “[...] como eu sinto Jesus em você, penso num só... agora fica só você na cabeça... parece que Jesus está no seu corpo... quando tem muita gente, a cabeça esquenta". Essa capacidade meditativa adquirida pela mulher [função psicológica do animus na mulher - que permite uma compreensão do inconsciente - ] terminou por aumentar sua capacidade de manejo em relação às crises, tornou-a capaz de apaziguar a multidão.

O desenvolvimento da capacidade compreensiva permitiu paz para uma apercepção intencional da paciente sobre a mater ecclesiae: “[...] quero escrever minha vida para as pessoas verem... a vida da santa". Antes oprimida pela imagem que ordenava na alucinação e na vivência delirante, agora estava livre, organizada pela meditação em Jesus com possibilidade de assimilação do valor da mater ecclesiae.

Gradativamente, uma atitude de compreensão e de laço social objetivo com o motivo típico da mater ecclesiae permitiu laço entre o sistema irracional individual com o coletivo, que, como nos informa Jung (1986), é o objetivo da análise das psicoses. O subjetivismo exacerbado é que aliena e impede o poder de contratualidade e, consequentemente, dificulta a reabilitação psicossocial (Melo, 2007).

Apaziguadas as crises, a intenção da mulher se dirigia agora para o simbolismo da mater ecclesiae: à delegação do ordenamento da psique a Jesus seguiu-se a necessidade de contratualidade relacional com aquele "[...] bem querer exagerado a todo mundo" (similar ao amor de Maria). No entanto, como a apercepção não suporta a assimilação do arquétipo em si, tal experiência de identidade e indiferenciação com todas as coisas mostrava que a usuária precisava ser orientada a assimilar parte das qualidades da mater ecclesiae, não se identificando com o arquétipo (Campbell, 2006).

A compensação arquetípica da grande mãe no lugar da mãe devoradora ganhava, agora, a necessidade de realizar a diferenciação psíquica orientada no Bardo Thödol (livro tibetano dos mortos): tratase de uma orientação aos "mortos" (ou iniciados) para que não se identifiquem ou não tomem qualquer visão ou manifestação de formas durante a travessia da morte (ou surto) como reais. O que precisava ser vivenciado pela mulher foi vivenciado no surto e 
durante todos os anos em que as imagens ainda lhe custaram a saúde. Do que ela precisava agora era de um guia que a orientasse com segurança, ao fim dessa jornada inconsciente, da melhor maneira possível (J esuino \& Simões, 2014).

Trata-se do motivo psicológico do renascimento, paralelo claro com o mito do herói solar (Jung, 1995), engolido no oceano e que depois chega à terra firme. Semelhante à ideia de Ronald Laing (1978) - no livro A Política da Experiência - sobre o surto psicótico como metanoia a partir da experiência de Jesse Watkins. No capítulo Uma viagem de dez dias, Watkins relata seu surto, explicando probabilidades de perigo e importância decorrentes dessa experiência: primeiro, os prováveis perigos que implicam a própria experiência sem um acompanhamento apropriado; segundo, o risco de ser impedido de passar pela experiência, uma vez cônscio da transformação de sentidos que implicou em sua vida.

\section{Refiguração: de quem é a ressocialização?}

Por último, tratamos por refazer as leituras da interpretação do método junguiano articuladas de modo complementar aos significados produzidos no processo psicoterapêutico dentro do contexto de vida da mulher; fazer isso implica voltar com a resposta da questão: "E o que é isso tudo na vida da usuária?".

Após a organização da paciente, revelou-se seu mistério: não ter aprendido a se valorizar no relacionamento com as pessoas a levou ao adoecimento. A religião, através das imagens de Jesus e Maria, veio como exigência de assimilação de conteúdos inconscientes que a ela se impunham para reordenar sua atitude diante da vida.

Com efeito, apesar do medo da energia das "forças de dominação" que ameaçavam levá-la ao surto quando a usuária tentava ir à igreja - que, simbolicamente, é nada mais nada menos que a própria mater ecclesiae (Jung, 1991a) -, ela mostrou-se disposta a superá-lo. Sincronisticamente (Jung, 1991b), no momento da proposta à paciente para a clínica peripatética (Lancetti, 2009) na igreja, ela assegurou que, com uma semana de antecedência, teria pressentido tal visita através de uma visão: "Já vi eu e você [sic] na igreja... já tinha visto nós dois lá, olhando os santos...".

Assim, na zona urbana onde fica o CAPS, fomos à Igreja Matriz equipamento (Lima \& Yasui, 2014) de tonalidade afetiva (Jung, 1991b) fundamental no território vivo da usuária (Lima \& Yasui, 2014) - e lá realizamos um atendimento. A mulher disse que se sentiu "[...] como se tivesse ido a uma missa", algo que ela deixou de fazer há bastante tempo. Aquelas forças que sentia naquele recinto, as mesmas do surto quando viu a santa no teto de sua casa, simbolizam Nossa Senhora e igreja, pois ambas são imagens da mater ecclesiae. 
Apesar da felicidade de ter ido à igreja, afirmava estar triste porque, em casa e na comunidade, sua religião era associada à "doença mental" devido aos episódios de surtos. Por conseguinte, nos trabalhos subsequentes, fizemos uma visita domiciliar à casa da paciente e realizamos um atendimento à família. Foi trabalhada a associação entre religião e o estigma "doença mental" na vida da usuária, evidenciando que, naquele momento, aquilo que eles aprenderam como sinal de adoecimento agora era possibilidade de equilíbrio.

Com a colaboração da família, terapeuta e usuária também visitaram a igreja da localidade onde ela morava, território vivo de afetos mais intensos (Lima \& Yasui, 2014). Fizemos parceria com trabalhadores da casa em uma espécie de matriciamento, semelhante ao que foi feito com a família, para trabalhar a dissolução da associação entre o estigma "doença mental" e religião com os trabalhadores da igreja. Combinamos que ela participaria do terço das mulheres, as quais a ajudariam nas leituras e a ensinariam a rezar o terço e o rosário. 0 forte interesse da mulher por essa questão se manifestou após a visão da santa.

Terço e rosário são rituais simbólicos de Maria. Portanto, trata-se de óbvia assimilação da qualidade santidade, antes em estado de identidade com Nossa Senhora (Jung, 1984) e alienada com os tratamentos psiquiátricos ofertados. Assim, a transcendência do estigma "doença mental" da experiência da usuária, atribuído pela cultura psiquiátrica à mater ecclesiae, deu lugar à busca da qualidade santidade: na relação com a igreja, com as orações à santa, com a família, com a comunidade, sendo possibilidade de saúde mental da própria personalidade, e na relação com o corpo da sociedade: “[...] depois que eu fiquei boa, as coisas mudaram, eu vou pra [sic] igreja e não tenho mais vergonha de entrar... as pessoas respeitam, a família respeita... falei pro [sic] padre sobre a santa... ele disse que eu fizesse uma caridade $[. .$.$] eu rezo... eu passei a querer mais bem à família,$ paramos de brigar... mais unidos, impossível".

À alegria de ter o coração no peito, finalmente, o sentimento de autocontrole, que outrora ela nomeara por coração na cabeça pela ação dos fármacos. Estes passaram a ajudá-la sem dopá-la: “[...] sinto controlada, tudo em ordem, faço [produto artesanal em casa, típico da região onde mora], não tem preguiça... não durmo muito". Assim, a usuária também voltou a trabalhar: “[...] eu tinha desgosto porque não podia trabalhar fazia mais de anos, toda semana agora eu faço [o produto artesanal]".

Segundo percebemos, a noção de "nova atitude adquirida", de Jung (1991, pp. 4-5), pela análise para uma vivência simbólica capaz de transformar a atitude pelo próprio sujeito, que citamos anteriormente, está em consonância com a ideia de saúde como capacidade de enfrentamento das adversidades que surgem ao longo da vida, de 
Georges Canguilhem (2002). A comparação entre os conceitos de Jung e de Canguilhem revela um único motivo: um conceito de saúde como tendência da capacidade de adaptação individual do sujeito pela criação de novas normas coletivas de adaptação subjetiva. 0 motivo que embasa tais ideias de saúde tem a vantagem de não ser utópico, como o da Organização Mundial da Saúde (OMS), tampouco produtor de estigmas por um estreito "caminho da normalidade" limítrofe com "desvios patológicos" coletivamente estabelecidos.

Destacamos ainda, como consequência dos atendimentos, a redução de danos pelo uso excessivo de psicofármacos, uma vez que a usuária parecia viver "[...] um transtorno por consumo de substâncias legitimado socialmente" (Jesuino \& Simões, 2014, p. 164), pois antes "[...] sentia que o remédio era forte... era barroando [sic] nas paredes de casa...". E ainda entrava em novas crises! A paciente arremata tal observação simbolicamente com a afirmação: "[...] o médico ficava do outro lado da mesa, contando história e passando remédio controlado... quem tinha que contar era eu! [a história do mito na sua vida]".

A substituição do modelo manicomial pelo modelo aberto e comunitário, sob a égide do cuidado em liberdade, provou que o ambiente de institucionalização levava mais à cronificação do adoecimento que a uma melhora dos sujeitos (Basaglia, 2005). Vale ressaltar, no entanto, que esse cuidado em liberdade do pensamento basagliano nasceu na década de 1970, mesmo período em que houve o desenvolvimento significativo da psicofarmacologia: "Mas depois que a ação dos fármacos demonstrou concretamente para o psiquiatra que ele não estava diante de uma doença, mas de um homem doente, não se pode continuar considerando este homem apenas como um excluído, de quem a sociedade quer ser protegida" (Basaglia, 2005, p. 54). Entretanto, essa confluência de acontecimentos da Reforma Italiana e da psicofarmacologia, na década de 1970, terminou por entrelaçar, de forma tenaz, o cuidado em liberdade e a química desses medicamentos (Jesuino \& Simões, 2014). Assim, o cuidado em meio aberto que o CAPS implica por vezes está distante de significar liberdade.

No último exame mental psiquiátrico da usuária, um ano após o fim da análise, dizia: "[...] bom aspecto geral, sem queixas, cooperativa, orientada e eutímica". Há mais tempo que esse registro já não identificava mais confusão, baixa cooperação, delírio místico, autocrítica e juízo crítico prejudicados. Tais construtos nosográficos da psiquiatria não encontravam mais o objeto do aumento dos antipsicóticos.

Ocupamo-nos da desinstitucionalização de tudo aquilo que se construiu em torno do adoecimento da usuária: propusemo-nos a pôr entre parênteses o diagnóstico enquanto construto objetificador da cultura psiquiátrica sobre a experiência do sujeito para entrar em 
contato com o sujeito no direcionamento do seu interesse para o material da sua experiência - como vimos, para um construto bem diverso do psiquiátrico (Amarante, 1996; Jung, 1986).

Dessarte, o contato com o sujeito nos foi facilitado pela obra de Jung (1986), pois o método construtivo convida o indivíduo da experiência psicótica para ser protagonista da construção de sentido sobre sua experiência subjetiva, terminando por se tornar possibilidade de transformação da sua personalidade em relação com a sociedade (individuação).

Complementar é Barreto (2011), venturoso ao afirmar que, embora possa haver derivação biológica, a emergência dos processos psicológicos possui uma autopoiese, podendo interferir em fatores emocionais, cognitivos e biológicos, o que está de acordo com a posição de Jung (1972) sobre a questão anatomofisiológica das psicoses. Barreto (2011), em seu trabalho sobre as contribuições de Eugen Bleuler (1857-1939), reconheceu propriedade em Gaetano Benedetti, fundador da International Society for Psychological and Social Approaches to Psychosis (ISPS), que afirmou "[...] [a psicose] se desenvolve em níveis estruturalmente elevados, onde os sintomas se entrelaçam com os símbolos e a experiência de vida" (p. 29). Nós, neste relato de caso, reconhecemos o método de Jung tanto na psicoterapia das psicoses quanto em uma precursora ética de desinstitucionalização.

\section{Considerações finais}

A complexidade da existência-sofrimento relatada evidenciou que 0 sofrimento por quadros psicóticos pode servir também para sua própria reabilitação psicossocial através do método junguiano.

O acompanhamento das ditas alucinações e delírios como solo de construção com base na psicologia analítica foi complementado pela atenção psicossocial para que a subjetividade fosse alcançada na ampliação da clínica ao território, permitindo novas conexões e pontos de partida, novos atores humanos e não humanos no processo terapêutico (Moraes, 2003).

Podemos destacar a ausência do matriciamento na atenção básica (Gondim, Simões, Neto, Vasconcelos, \& J orge, 2014) como limitação prática do estudo dessa clínica territorial, embora este relato amplie a noção de matriciamento para além da saúde, considerando as conexões práticas do caso com a igreja como equipamento de saberes e práticas direcionado para a proteção diante de fenômenos Inconscientes (J ung, 1965).

O trabalho no serviço evidenciado por este caso na condição de residente termina por destacar o espaço protegido para agregar prática e estudo na formação da residência, uma vez que oferece 
condições para maior dedicação aos atendimentos, pois somos orientados a atender menos casos que os profissionais de referência dos serviços. A experiência com este caso contribuiu para a articulação entre clínica individual e ampliada, desmistificando sua falsa dicotomia, uma vez que experimentar a psicologia como ferramenta de invenção de possibilidades de desenvolvimento existencial a partir de limites subjetivos mostrou que a incompatibilidade está mais ligada a atitudes e compreensões dos profissionais que a inconciliação entre métodos e paradigmas científicos.

Isso envolveu, sobremaneira, uma ressocialização de visão de mundo semelhante ao que Castañeda (1971, pp. 9-11) articula sobre os "estados de consciência alterada", evidenciando a necessidade de desmantelamento da visão sensata de mundo através de uma acessibilidade, que ele chama "ressocialização", por um "sistema de interpretação sensata" para aqueles novos dados perceptíveis à consciência. Em outras palavras, destacamos o quanto o simbolismo das imagens inconscientes (Jung, 1986) pode contribuir para recuperar a subjetividade como materialidade psicológica emancipada (Lane, 1984).

Assim, trata-se da ressocialização entre o sistema irracional manifesto na usuária e as imagens similares dos sistemas irracionais consolidados em símbolos culturais (Jung, 1986) pertencentes à cultura dela própria enquanto sujeito histórico (Lane, 1984), mas, graças à negatricidade (Palmieri, 2008) da usuária aos construtos psiquiátricos, ela foi além da determinação histórica: pôde ser construtora ou, nas palavras de Lane (1984), produtora de sua própria história. Seu discurso antes patologizado passou a experimentar possibilidade de emancipação, que chamamos desinstitucionalização da subjetividade psicótica.

Simbolicamente, aquele estado psicológico de cisão que sonhava juntar as duas personalidades, "a do coração na cabeça" e "a do coração no peito", não era mais impossível. Os corações opostos estavam agora em um só, pela simbólica da mater ecclesiae, sustentando aquela ansiada possibilidade de amor ao próximo: como o sagrado coração de Jesus e Maria.

Como vimos, a vida psíquica que em si apresentava à mulher algo da ordem da sensação do mysterium tremendum et fascinans (Otto, 2011) a levou ao desespero e à internação por profissionais tanto ou mais amedrontados. Terão sido os mesmos medo e incompreensão que levaram à insistência no centramento unilateral na medicação mesmo em meio aberto? A resposta exige mais experiências psicoterapêuticas das psicoses, como reclama a usuária do estudo. Nós defendemos mais experiências construtivas.

Se não encararmos tal medo, de que outro modo a vida dessas pessoas pode evitar terminar sem um sentido para o qual viver? $\mathrm{Na}$ 
dúvida sobre qual biografia gostaria de contar, se a dela ou a da santa, a mulher nos respondeu com seu próprio compromisso, o qual outrora lhe aterrorizou.

\section{Referências}

Alverga, A. R., \& Dimenstein, M. A. (2006). A reforma psiquiátrica e os desafios na desinstitucionalização da loucura. Interface: comunicação, saúde, educação, 10, 229-316.

Amarante, P. (1996). O homem e a serpente: outras histórias para a loucura e a psiquiatria. Rio de Janeiro: Fiocruz.

Barreto, E. (2011). A influência de Bleuler no desenvolvimento de formas de intervenção psicológica na esquizofrenia e na psicose. Revpsiq: Revista de Psiquiatria. 25, 1-32.

Basaglia, F. (2005). Escritos selecionados em saúde mental e reforma psiquiátrica. Rio de Janeiro: Garamond.

Bíblia Sagrada. (1990). Edição pastoral. São Paulo: Paulus.

Campbell, J. (2006). Esquizofrenia: a jornada interior. In J. Campbell. Para viver os mitos (pp. 162-186). São Paulo: Cultrix.

Canguilhem, G. (2002). O normal e o patológico. Rio de Janeiro: Forense Universitária.

Castañeda, C. (1971). Uma estranha realidade. Rio de Janeiro: Nova Era.

Costa, F., Jr., \& Medeiros, M. (2007). Alguns conceitos de loucura entre a psiquiatria e a saúde mental: diálogos entre os opostos? Psicologia USP, 18, 57-82.

Gondim, L. G. F., Simões, E. C. P., Neto, J. M. P., Vasconcelos, M. G. F., \& Jorge, M. S. B. (2014). Possibilidades e desafios do apoio matricial na atenção básica: percepções dos profissionais. Psicologia: Teoria e Prática, 16, 63-74.

Jesuino, F. M. \& Simões, E. C. P. (2014). Amarga fronteira entre a crítica e a transformação: considerações psicológicas sobre a humanização na atenção à loucura. In F. M. Jesuino (Ed.) IMPETUS - Psicologia Mitologia Cultura (pp. 159-257). Fortaleza: Ana Lima.

J ung, C. G. (1965). Psicologia e religião. Rio de Janeiro: Zahar.

Jung, C. G. (1972) Letter to the Second International Congress of Psychiatry (Symposium on Chemical Concepts of Psychosis). In C. G. Jung Collected Works of C. G. Jung, 3, Princeton University., 1852.

Jung, C. G. (1984). O segredo da flor de ouro. Petrópolis: Vozes.

Jung, C. G. (1985). Psicologia do inconsciente. Petrópolis: Vozes.

Jung, C. G. (1986). Psicogênese das doenças mentais. Petrópolis: Vozes.

Jung, C. G. (1988). Presente e futuro. Petrópolis: Vozes. 
Jung, C. G. (1991a). A natureza da psique. Petrópolis: Vozes.

Jung, C. G. (1991b). Fundamentos de psicologia analítica. Petrópolis: Vozes.

Jung, C. G. (1995). Símbolos da transformação. Petrópolis: Vozes.

Jung, C. G. (2008). Aion: estudos Estudos sobre o simbolismo do Simesmo. Petrópolis: Vozes.

Laing, R. (1978). A política da experiência e a ave-do-paraíso. Petrópolis: Vozes.

Lancetti, A. (2009). Fontes da clínica peripatética. In A. Lancetti. Clínica peripatética (pp. 19-37). São Paulo: Hucitec.

Lane, S. T. M. (1984). A Psicologia Social e uma nova concepção do homem para a Psicologia. In S. T. M. Lane \& W. Codo, Psicologia Social: o homem em movimento (pp. 10-19). São Paulo: Brasiliense.

Lima, E. M. F. A., \& Yasui, S. (2014). Territórios e sentidos: espaço, cultura, subjetividade e cuidado na atenção psicossocial. Saúde debate, 38, 593-606.

Melo, W. (2007). Maceió é uma cidade mítica: o mito da origem em Nise da Silveira. Revista Redalyc: Sistema de redação científica, 18, 101-124.

Moraes, M. (2003). A Psicologia como reflexão sobre as práticas humanas: da adaptação à errância. Estudos de Psicologia, 8 (3), 535-539.

Otto, R. (2011). O sagrado. Petrópolis: Vozes.

Palmieri, M. W., \& Martins, J. B. (2008). Possibilidades e desafios da produção científica no campo da Psicologia: algumas reflexões. Psicologia em Estudo, 13(4), 743-752.

Pessotti, I. (2006). Sobre a teoria da loucura no século XX. Revista Temas em Psicologia, 14, 113-123.

Rotelli, F. A instituição inventada. (1990). In R. F. Nicácio. Desinstitucionalização (pp. 89-99). São Paulo: Hucitec.

\section{Endereço para correspondência}

Emanuel Cesar Proença Simões

Universidade Federal de São J oão del-Rei - UFSJ

Praça Dom Helvécio, 74, Campus Dom Bosco, PPGPSI - Sala 1.53, CEP 36301-160,

São J oão del-Rei - MG, Brasil

Endereço eletrônico: emceprosi@gmail.com

Filipe de Menezes J esuino

Dialogus Clínica de Psicologia

Rua Waldery Uchoa, 5, Benfica, CEP 60020-110, Fortaleza - CE, Brasil

Endereço eletrônico: filipemjesuino@gmail.com

Recebido em: 28/09/2015

Aceito em: 29/12/2016 


\section{Notas}

* Psicólogo pela Universidade Estadual do Ceará - UECE, especialista em saúde mental coletiva pela Residência Integrada em Saúde da Escola de Saúde Pública do Ceará - RIS/ ESP-CE, mestrando em psicologia pela Universidade Federal de São J oão del-Rei - UFSJ .

** Psicólogo, Mestre em Psicologia e Doutor em Educação pela Universidade Federal do Ceará - UFC. 